\title{
ENSINO DE NUTRIÇÃO NAS ESCOLAS DE ENFERMAGEM DO ESTADO DE SÃO PAULO
}

\author{
Leda Ulson Mattos* \\ Aracy Witt P. Spinola** \\ Hisako Shima*** \\ Maria Josefina Leuba Salum***
}

\begin{tabular}{l|c|}
$/ 14$ \\
\hline
\end{tabular}

MATTOS, L.U. e colaboradores - Ensino de nutriçāo nas escolas de enfermagem do Estado de Sāo Paulo. Rev. Bras. Enf.; DF, 29 : 115-126, 1976.

Considerando-se que o cuidado nutricional do paciente é uma das responsabilidades de fato do enfermeiro em nosso meio, seria de interesse verificar se o profíssional de enfermagem está recebendo uma formação que lhe permita adquirir conhecimentos e habilidades relativas à nutrição, exigidas pelas demandas do campo.

Entende-se aqui como cuidado nutricional o conjunto de atividades relacionadas: orientação do paciente, da familia ou da comunidade sobre sua dieta, supervisão da aceitação desta, avaliação da mudança de comportamento alimentar, colaboração com a nutricionista no planejamento da dieta e na sua administração.
O "Secretary's Comittee" (Departament of Health, Education and Welfare, WASHINGTON DC) que estudou, em 1972, os diversos papéis desempenhados pelo enfermeiro, revela que a expectativa em relação ao profissional de enfermagem é a sua atuação como membro responsável da equipe de saúde, interpretando $e$ desempenhando instruçōes dos outros membros, colaborando no planejamento e implantação dos serviços de saúde ou agindo independentemente. Para tanto, deve ter o enfermeiro formação que lhe permita desempenhar tais papéis. Em relação ao cuidado com a nutrição do paciente, o enfermeiro de Saúde Pública, por exemplo, "tem supervisionado a dieta na gestação e na in-

- Professor Livre-Docente da disciplina Nutriçāo e Dietética Aplicadas à Enfermagem, da EEUSP.

** Professor Livre-Docente do Departamento de Prática de Saúde Pública da Faculdade de Saúde Pública da USP.

*** Auxiliares de Ensino da disciplina Nutriçāo e Dietética Aplicadas à Enfermagem, da EEUSP. 
MATTOS, L.U. e colaboradores - Ensino de nutrição nas escolas de enfermagem do Estado de São Paulo. Rev. Bras. Enf.; DF, 29 : 115-126, 1976.

fância; de um modo geral, tem sido o profissional de enfermagem responsável pela educação da paciente e da familia no seguimento do dieta, levando em conta antecedentes culturais, preferências pessoais e condiçōes financeiras".

HARRISON e Col. (1969) fizeram um levantamento entre os enfermeiros em Saúde Pública para verificar os seus conhecimentos de nutrição e dietoterapia. Mediram quatro categorias de conhecimentos de nutrição consideradas desejáveis para enfermeiros: a) instrumentos comuns utilizados na avaliação de dietas; b) fatores fisiológicos que interferem na ingestão do alimento; c) fatores psicológicos, culturais, sociais e econômicos que interferem na ingestão de alimento; d) nutrientes constituintes dos alimentos. Os resultados mostraram grande variação nas áreas de conhecimento da nutrição estudada. Por um lado, houve maior variação nas categorias sobre conhecimento de fatores fisiológicos e psicológicos que interferem na ingestão de alimentos e necessidades nutricionais, e, por outro, verificou-se a ausência de conhecimentos sobre os instrumentos usados na avaliação e planejamento das dietas. Os enfermeiros com grau de bacharel apresentaram valores significativamente mais altos, ao passo que os enfermeiros atuantes não apresentaram diferenças em relação ao tipo de formação. No mesmo trabalho, os autores citam que nos Estados Unidos o nutricionista de agência de saúde provê a educação e atualização do enfermeiro em Saúde Pública em assuntos de nutrição. $O$ estudo indicou ainda que o nutricionista, o enfermeiro supervisor e outros enfermeiros do "staff" são freqüentemente consultados pelos enfermeiros em Saúde Pública sobre assuntos de nutrição.

CICONELLI e Col. (1970) citam como uma das funçōes do enfermeiro hospitalar, auxiliar o paciente a recuperar- se e manter a saúde, e propōem como uma das atividades do enfermeiro "observar a reação do paciente, relativamente à dieta que lhe foi prescrita" e "orientar os familiares sobre visitas, doação de sangue e tratamento, no momento da admissão do paciente, e sobre dieta, curativos, medicação e retorno na ocasião da alta hospitalar".

COELHO e Col. (1970) descrevem a distribuição das atividades dos membros da equipe de trabalho no serviço de puericultura do $5 .^{\circ}$ Centro de Saúde e Unidade Sanitária de ensino em Amaralina, sendo função do enfermeiro pediátrico elaborar um plano de assistência de enfermagem à criança, no qual um dos itens é a orientação dietética para as diferentes idades.

Nos relatórios dos grupos de trabalho do II Seminário sobre Educação em Enfermagem realizado na Escola de Enfermagem de Ribeirão Preto (OPAS/OMS, 1970) - tema referente ao currículo do Curso de Graduação em Enfermagem -, concluiu-se que uma das atividades especificas da assistência de enfermagem, na área de Enfermagem Materno-Infantil é o cuidado com a alimentação do recém-nascido, lactente, pré-escolar e escolar.

Não bastassem tais verificaçōes, sabese que a Nutrição tem feito parte do elenco de disciplinas do curso de graduação em Enfermagem desde a implantação do ensino de Enfermagem em nosso país, remontando tal fato aos primórdios da sistematização do ensino de Enfermagem. Isto vem refletir o interesse dos educadores de Enfermagem em adequar o ensino à realidade que encontram os profissionais no campo.

Propôs-se nesse trabalho a verificar a situação do ensino de nutrição nas escolas de Enfermagem do Estado de São Paulo, com a finalidade de averiguar quais as disciplinas ministradas e de 
MATTOS, L.U. e colaboradores - Enstno de nutrição nas escolas de enfermagem do Estado de Sāo Paulo. Rev. Bras. Enf.; DF, 29 : 115-126, 1976.

que forma, bem como o parecer dos alunos sobre o assunto.

Acredita-se que as observaçōes obtidas possam ser de utilidade na adequação do ensino, uma vez que fornecem visão do que está ocorrendo e de como isto é percebido pela população estudantil. Deve-se ressaltar que tal percepção reflete as necessidades sentidas pelos alunos, podendo estas constituir subsídios para a elaboração de programas de ensino.

Partiu-se da suposição de que as disciplinas Nutrição Norm̈al, Dietoterapia, Nutrição Infantil, Dietoterapia Infantil, Nutrição em Saúde Pública, Nutrição da Gestante e Puerpério ,são ministradas em todas as Escolas de Enfermagem do Estado de São Paulo, mas de forma heterogênea, ora isolada, ora integrada a outras disciplinas de Enfermagem.
As escolas que fizeram parte do estudo foram: Escola de Enfermagem da USP, Faculdade de Enfermagem São José, Faculdade Adventista de Enfermagem, Escola Paulista de Enfermagem, Escola de Enfermagem de Ribeirão Preto (USP), Escola de Enfermagem da Pontifícia Universidade Católica (São Paulo), Escola Superior de Enfermagem (Mogi das Cruzes), Faculdade de Enfermagem da Pontifícia Universidade Católica (Campinas).

Os estudantes submetidos à pesquisa foram os que cursaram o último semestre do curso de graduação em Enfermagem nas escolas citadas, presentes por ocasiāo da visita do pesquisador e que perfizeram 0 total de 244, assim distribuídos:

Tabela 1 - População estudantil distribuida por escolas:

\begin{tabular}{c|c|c|c}
\hline Escola & $\begin{array}{l}\text { Alunos } \\
\text { matriculados }\end{array}$ & \multicolumn{2}{c}{$\begin{array}{c}\text { Alunos que responderam } \\
\text { o ques tionário }\end{array}$} \\
\cline { 2 - 4 } & F & F & $\%$ \\
\hline A & 76 & 61 & 80,3 \\
C & 40 & 22 & 55,0 \\
D & 25 & 13 & 52,0 \\
E & 13 & 6 & 46,2 \\
F & 75 & 54 & 72,0 \\
G & 49 & 31 & 63,3 \\
H & 51 & 32 & 62,8 \\
Total & 25 & 25 & 100,0 \\
\hline
\end{tabular}

A coleta de dados teve por base um questionário, constituído de acordo com a metodologia apregoada pelas Ciências Sociais tendo-se em vista a validade das informaçōes coletadas.

As instruçōes para o preenchimento do questíonário foram dadas oralmente, logo após a sua distribuição, sendo feitos os esclarecimentos, em relação a cada item antes do seu preenchimento.
Os dados foram tabulados e serão apresentedos a seguir.

A Tabela 2 contém as respostas afirmativas dadas pelos estudantes, a respeito do ensino das disciplinas alvo do estudo.

Como pode ser visto, a disciplina $\mathrm{Nu}-$ trição Normal obteve maior freqüência de respostas afirmativas, correspondendo a um total de $99,2 \%$, e a menor freqüên- 
MATTOS, L.U. e colaboradores - Ensino de nutrição nas escolas de enfermagem do Estado de São Paulo. Rev. Bras. Ene.; DF, 29 : 115-126, 1976.

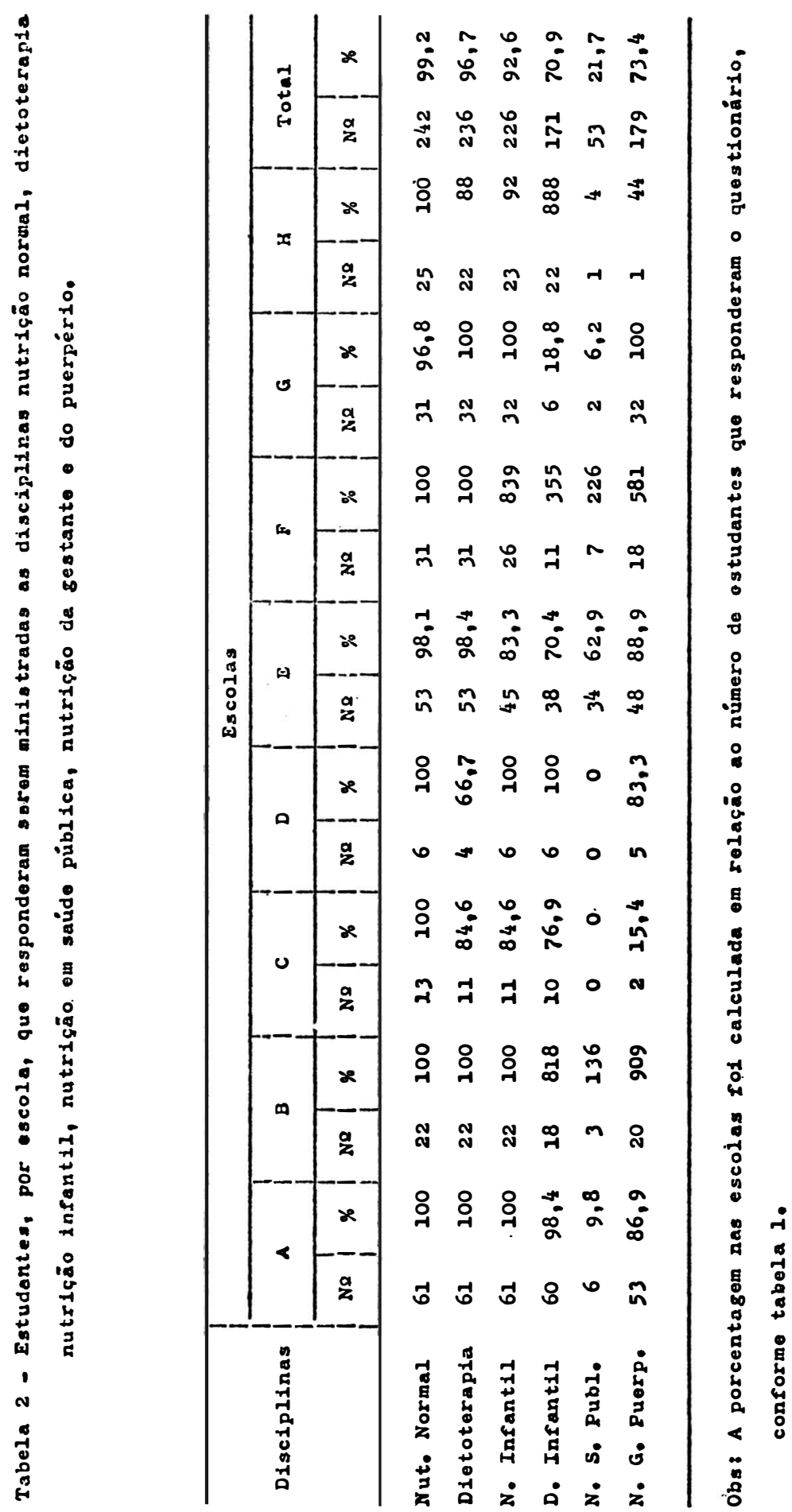


MATTOS, L.J. e colaboradores - Fnsino de nutriçáo nas escolas de enfermagem do Estado de 880 Paulo. Bev. Brae Enf.; DF, 29 : 115-126, 1976.

Tabela 3 - Disciplinas ministradas, segundo a forma - isolada ou integrada en disciplina de enfermagem.

\begin{tabular}{|c|c|c|c|c|c|c|c|}
\hline $\begin{array}{l}\text { ES } \\
\text { Co } \\
\text { LA }\end{array}$ & $\begin{array}{l}\text { DISC } \\
\text { FORMA }\end{array}$ & $\begin{array}{l}\text { Nutrição } \\
\text { Normal }\end{array}$ & $\begin{array}{l}\text { Dietote } \\
\text { rapia }\end{array}$ & $\begin{array}{l}\text { Nutrição } \\
\text { Infantil }\end{array}$ & $\begin{array}{l}\text { Dietote } \\
\text { rapia } \\
\text { Infantil }\end{array}$ & $\left\{\begin{array}{l}\text { Nosaúde } \\
\text { Pública }\end{array}\right.$ & $\begin{array}{l}\text { Nutriçāo } \\
\text { gest. } \\
\text { puerpério }\end{array}$ \\
\hline $\mathbf{A}$ & $\begin{array}{l}\text { Isolada } \\
\text { Integrada } \\
\text { n. respondeu }\end{array}$ & $\begin{array}{c}61(100) \\
\vdots\end{array}$ & $\begin{array}{c}57(93,4) \\
4(6,6)\end{array}$ & $\begin{array}{c}56(91,8) \\
5(8,2) \\
-\end{array}$ & $\begin{array}{r}8(1,3,1) \\
52(85,2) \\
1(1,7)\end{array}$ & $\begin{array}{r}1(1,6) \\
5(8,2) \\
55(90,2)\end{array}$ & $\begin{array}{r}53(8 \overline{6}, 9) \\
8(13,1)\end{array}$ \\
\hline B. & $\begin{array}{l}\text { Isolada } \\
\text { Integrada } \\
\text { n. respondeu }\end{array}$ & $\begin{array}{c}22(100) \\
-\end{array}$ & $\begin{array}{c}22(100) \\
= \\
-\end{array}$ & $22\left(\begin{array}{l}- \\
-\end{array}\right.$ & $\begin{array}{r}18(81,8) \\
4(18,2)\end{array}$ & $\begin{array}{r}3(13,6) \\
19(86,4)\end{array}$ & $\begin{array}{r}21(95,5) \\
1(4,5)\end{array}$ \\
\hline C & $\begin{array}{l}\text { Isolada } \\
\text { Integrada } \\
\text { n. respondou }\end{array}$ & $\begin{array}{c}13(100) \\
=\end{array}$ & $\begin{array}{r}11(84,6) \\
2(15,4)\end{array}$ & $\begin{array}{r}11(8 \overline{4}, 6) \\
2(15,4)\end{array}$ & $\begin{array}{r}10(7 \overline{6}, 4) \\
3(23,1)\end{array}$ & $13(\stackrel{-}{100})$ & $\begin{array}{r}2(15,4) \\
1 i(84,6)\end{array}$ \\
\hline D & $\begin{array}{l}\text { Isolada } \\
\text { Integrada } \\
\text { n. respondeu }\end{array}$ & $\begin{array}{c}6(100) \\
\cdots\end{array}$ & $\begin{array}{c}4(66,7) \\
2(33,3) \\
\end{array}$ & 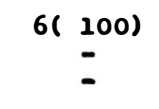 & 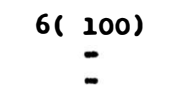 & $6\left(\frac{-}{100}\right)$ & $\begin{array}{c}6(100) \\
- \\
-\end{array}$ \\
\hline $\boldsymbol{E}$ & $\begin{array}{l}\text { Isolada } \\
\text { integroda } \\
\text { n. respondeu }\end{array}$ & $\begin{array}{c}53(100) \\
-\end{array}$ & $\begin{array}{r}5(9,3) \\
40(74,1) \\
9(16,6)\end{array}$ & $\begin{array}{r}5(9,3) \\
45(83,3) \\
4(7,4)\end{array}$ & $\begin{array}{l}1(5,4) \\
39(72,2) \\
14(25,9)\end{array}$ & $\begin{array}{r}2(3,7) \\
32(59,3) \\
20(37,0)\end{array}$ & $\begin{array}{r}5(9,3) \\
41(75,9) \\
8(14,8)\end{array}$ \\
\hline $\boldsymbol{F}$ & $\begin{array}{l}\text { Isolada } \\
\text { integrada } \\
\text { n. respondeu }\end{array}$ & $\begin{array}{c}31(100) \\
=\end{array}$ & $\begin{array}{c}31(100) \\
=\end{array}$ & $\begin{array}{r}3(9,7) \\
23(74,2) \\
5(16,1)\end{array}$ & $\begin{array}{r}2(6,5) \\
9(29,0) \\
20(64,5)\end{array}$ & $\begin{array}{r}4(13,0) \\
3(9,6) \\
24(77,4)\end{array}$ & $\begin{array}{r}4(12,9) \\
14(45,2) \\
13(41,9)\end{array}$ \\
\hline G & $\begin{array}{l}\text { Isoleda } \\
\text { integrada } \\
\text { n. respondeu }\end{array}$ & $\begin{array}{c}31(96,8) \\
1(3,2)\end{array}$ & $\begin{array}{r}5(15,6) \\
26(81,3) \\
1(3,1)\end{array}$ & $\begin{array}{c}29(90,6) \\
3(9,4) \\
0\end{array}$ & $\begin{array}{r}6(1 \overline{8}, 7) \\
26(81,3)\end{array}$ & $\begin{array}{r}2(\overline{6}, 3) \\
30(93,7)\end{array}$ & $32(100)$ \\
\hline H & $\begin{array}{l}\text { Isolada } \\
\text { Integrada } \\
\text { n. respondeu }\end{array}$ & $\begin{array}{c}25(100) \\
-\end{array}$ & $\begin{array}{r}18(72,0) \\
4(16,0) \\
3(12,0)\end{array}$ & $\begin{array}{r}2(8,0) \\
19(76,0) \\
4(16,0)\end{array}$ & $\begin{array}{r}2(8,0) \\
18(72,0) \\
5(20,0)\end{array}$ & $\begin{array}{r}3(12,0) \\
3(12,0) \\
19(76,0)\end{array}$ & $\begin{array}{r}4(16,0) \\
4(16,0) \\
17(68,0)\end{array}$ \\
\hline
\end{tabular}

Obs: 0 súmeros entre paxênteses Indicam as porcentagens, que foram calculadas en relaçāo ao número de estudantea que responderam o questionário em cada escola. 
MATTOS, L. U. e colaboradores - Ensino de nutrição nas escolas de enfermagem do Estado de São Paulo. Rev. Bras. Enf.; DF, 29 :115-126, 1976.

cia encontra-se na disciplina Nutrição em Saúde Pública, que alcançou a porcentagem de $21,7 \%$. Deve-se ressaltar que em duas escolas (C e D) verificouse que essa disciplina não tinha sido ministrada.

Apresenta porcentagem inferior a 75\%, a freqüência de respostas relativas ao ensino das disciplinas Dietoterapia Infantil $(\mathbf{7 0 , 9 \% )}$ e Nutrição da Gestante e do Puerpério $(73,4 \%)$, o que pode dever-se à forma integrada de ministrálas. A notar é que essa última disciplina aparece com porcentagem baixa nas escolas $\mathrm{H}(4 \%)$ e C $(15,4 \%)$.

A seguir são apresentados os resultados referentes à forma de ensino, que pode ser isolada ou integrada a uma disciplina de Enfermagem (Tabela 3 ).

Como se pode observar, as informações contidas na Tabela 3 nem sempre apresentam unanimidade por parte dos estudantes em identificar a forma de ensino das disciplinas da Nutrição. Apesar desse fato, consideram-se que as alternativas com maior freqüência pudessem ser representativas da realidade.

Segundo as respostas dos estudantes, a disciplina Nutrição Normal, além de ser ministrada em todas as escolas, o é de forma isolada.

Fm cinco escolas (A, B, D, F, H) os estudantes afirmaram ser a disciplina Dietoterapia ministrada de forma isolada, sendo que em duas delas (B e F) houve unanimidade em apontá-la como tal. Nas demais escolas verifica-se que a maioria dos estudantes informou ser dada de forma integrada. Na escola C, os estudantes referiram ser a disciplina Dietoterapia integrada à Nutrição Normal $(84,6 \%)$, na escola $G$ à disciplina Enfermagem Médico-Círúrgica $(81,3 \%)$ e na $\mathbf{E}$ informaram estar distribuída entre as disciplinas Nutrição Normal (35,2\%) e Enfermagem Cirúrgica $(33,3 \%)$.

A maioria dos estudantes das escolas A, D e G informou ser a disciplina Nu- trição Infantil ministrada de forma isolada $(91,8 \%, 100 \%$ e $90,6 \%$, respectivamente). A maior freqüência que indica ser aquela disciplina integrada à outra de Enfermagem encontra-se nas escolas B $100 \%)$ e C $(84,6 \%)$ seguindose da $E(83,3 \%)$, da $H(76 \%)$ e da $F$ $(74,2 \%)$. Na escola B referiram estar integrada à disciplina Enfermagem Pediátrica $(91 \%)$, bem como na escola $F$ $(\mathbf{7 9 , 2 \% )}$ e na escola $E \mathbf{( 7 5 , 9 \% )}$. Na escola $\mathrm{H}$ os estudantes não indicaram a que disciplina está integrada a Nutrição Infantil.

Quanto à disciplina Dietoterapia Infantil, verifica-se que na escola $D, 100 \%$ dos estudantes referiu ser ministrada de forma isolada. Nas escolas A, B, C, E e H, por outro lado, os estudantes em sua maioria informaram ser a disciplina ministrada de forma integrada, nas seguintes porcentagens: $85,2 \%, 81,8 \%, 76,4 \%$, $\mathbf{7 2 , 2 \%}$ e 72,0\%. Praticamente inexiste resposta sobre o assuntos nas escolas F e G. Na escola A os estudantes referiram estar essa disciplina integrada à Nutrição Infantil $(90,2 \%)$; na B, na C e na $\mathbf{E}$ à Enfermagem Pediátrica em porcentagens semelhantes $(77 \%, 79 \%$ e $\mathbf{7 0 , 3 \%}$, respectivamente). Não houve indicação de qual disciplina integra-a na escola $\mathrm{H}$.

A disciplina Nutrição em Saúde Pública apresenta falta de resposta, na maioria das escolas, o que se justifica pelos dados da tabela anterior, onde há informação de que ela não é ministrada nas escolas alvo do estudo. Na escola E, porém, $59,3 \%$ dos estudantes informou estar integrada à disciplina Enfermagem Materno-Infantil $(92,6 \%)$.

Finalmente, quanto à disciplina Nutrição da Gestante e do Puerpério, houve praticamente falta de informação nas escolas C e H. Nas demais escolas os estudantes referiram ser o seu ensino integrado ao de Enfermagem Obstétrica ou Materno-Infantil (escola E). Parece arriscado concluir, de algum modo, so- 
MATTOS, L.U. e colaboradores - Ensino de nutrição nas escolas de enfermagem do Estado de São Paulo. Rev. Bras. Enf.; DF, 29 : 115-126, 1976.

bre a forma de ensino dessa disciplina na escola $F$, uma vez que praticamente a mietade dos estudantes não informou nada a respeito.

Adicionalmente são apresentadas algumas informaçōes obtidas sobre as atividades práticas, realizadas pelos estudantes: experiências com animais, cálculo de dietas, preparo de dietas hospitalares, preparo de mamadeira, visitas a serviço de nutrição e dietética, visitas a lactário, visitas a indústrias de produtos almentícios, estudos de caso e cstági, em hospitais, são as atividades que aparecem com maior freqüência.

Como muitas informaçōes de valia são obtidas quando é dada oportunidade ao indivíduo de se manifestar, esse recurso foi utilizado na presente investigação. Praticamente não houve sugestōes que se referissem ao aumento do número de disciplinas que compōem o ensino da Nutrição; as observaçōes mais proveitosas ligam-se à metodologia de ensino utilizada, ou seja, ensino teórico, prático ou teórico-prático. Porém a análise das sugestōes dadas não permitiu que muitas respostas fossem enquadradas nas 3 modalidades citadas acima; assim, foram estabelecidas mais duas: estágio e aplicabilidade.

As sugestōes da modalidade ensino teórico foram as que se referiram a atividades tais como: teoria exemplificada, enfoque pluri-disciplinar, abordagem multiprofissional, conceituaçōes mais profundas, etc.

A sugestão da modalidade ensino prático mais freqüente foi a necessidade sentida pelos estudantes de serem as aulas ministradas em hospital. Além desta, foram sugeridas as seguintes: realização de experiências com animais, experiências em laboratório, preparo de fato de dietas hospitalares - sendo citados especificamente diabéticos, puérperas e ulcerosos - e maior contato com pacientes que recebem tratamento dietoterápico.

Em relação ao ensino teórico-prático foi apontada com freqüência a adequação das técnicas de trabalho educativo, isto é, desenvolvimento destas junto às mães e à família de pacientes.

Observação constante relativa ao estágio foi a de que deveria ser incluído um que fosse especificamente dirigido ao seguimento de pecientes sob tratamento dietoterápico.

Quanto às sugestōes da modalidade aplicabilidade temos: adaptação à realidade sócio-médica local, utilização imediata e específica, viabilidade econômica das dietas, condicionamento das dietas à época do ano, etc.

Destacam-se, ainda, no entanto, respostas dadas que exemplificam a metodologia de ensino considerada ideal tais como: necessidade de maior relacionamento entre Nutrição e Enfermagem, discussão de casos, maior adequação entre teoria e prática. Além destas sugeriuse maior aproximação entre os diferentes membros da equipe de saúde, como médicos e nutricionistas, para a elaboração conjunta de dietas.

A análise das respostas tabuladas (anexo) referentes às sugestōes ligadas às modalidades de ensino (categorias citadas anteriormente) mostra que foram emitidas 195 sugestōes, sendo que destas $42,05 \%$ referentes à prática, seguindo-se $33,33 \%$ relacionadas ao estágio. Esses dados, como outros, podem ser vistos na Tabela 4.

Considerando-se as várias disciplinas, observa-se que o maior número de sugestōes recai na disciplina Dietoterapia Infantil (40), seguindo-se a Nutrição Normal (38) e a Dietoterapia (35). A modalidade de ensino que recebeu maior número de referências foi a prática e em relação ao ensino da Dietoterapia. Portanto, essa disciplina, considerando- 
MATTOS, L. U. e colaboradores - Ensino de nutriçảo nas escolas de enfermagem do Estado de São Paulo. Rev. Bras. En̊.; DF, 29 : 115-126, 1976.

se os dados como um todo, é a que está necessitando de reformulação, com aumento da prática, segundo parecer de maior número de pesquisados $(12,31 \%)$; porém, considerando-se apenas as freqüências relativas à prática, essa porcentagem sobe para $29,27 \%$.

Como era esperado, há variaçāo entre as frequiências de sugestōes ligadas à teoria, prática, teoria e prática, estágio aplicabilidade entre as várias escolas. Das escolas pesquisadas, 5 apresentam maior número de respostas referindo-se à necessidade de número elevado de aulas práticas (A, B, C, E e F). As duas escolas que apresentam maior porcentagem nesse sentido são $B$ $(72,00 \%)$ e F $(48,00 \%)$; são, pois os estudantes dessas escolas os que mais desejam o aumento de ensino prático. A necessidade mals freqüente expressa nas demais escolas diz respeito a estágio, que em certo sentido equivalente à prática; tais sugestōes apresentam-se nas porcentagens de $83,33 \%$ na escola $D$, $60 \%$ na $\mathrm{H}$ e de $43,00 \%$ na $G$.

Os estudantes referiram a necessidade de mais prática e estágio na disciplína Nutrição em Saúde Pública. Isto talvez se deva à quase que inexistência do ensino dessa disciplina nas escolas estudadas. $O$ mesmo, praticamente, ocorre com a Dietoterapia Infantil; quanto a. Dietoterapia, como já vímos, a maior deficiência apontada se encontra na prática.

Considerando-se especificamente cada escola, na A fol apontada como necessidade prioritária maior número de aulas práticas na disciplina Nutrição Infantil. Na escola B, também aparece necessidade expressa de maior número de aulas práticas nas disciplinas Nutrição Normal, Dietoterapia e Dietoterapia Infantil. Na escola C, ressaltou-se novamente o maior número de sugestōes relativas à prática, porém, junto às discipinas Dietoterapia e Nutrição Infantil, e Nutrição da Gestante e Puerpério; a escola $D$, por sua vez, aponta em primeiro lugar a necessidade de mais estágio em todas as disciplinas com exceçāo de Dietoterapia. Isto parece estranho uma vez que é essa disciplina fundamentalmente relacionada à prática diária hospitalar dos estudantes. Por outro lado, durante as estágios especializados informalmente são oferecidas mais oportunidades no que se refere à aplicação dos conhecimentos de Dietoteapia, o que poderia justificar a falta de necessidade de estágio nessa disciplina. Na escola $\mathbf{E}$ há predominância de sugestōes relativas à prática citada em relação a todas as disciplinas (15), seguindo-se as referentes a estágio (14) em todas as disciplinas com exceção dn Nutrição Infantil. Na escola $\mathrm{F}$ houve maior número de sugestōes relativas à prática concentrando-se tals sugestōes na disciplina Dietoterapia. Na escola G aparece a necessidade de estágio em maior número relacionado à Dietoterapia Infantil e Nutrição em Saúde Pública. Finalmente, na escola $\mathrm{H}$, também predominam as sugestōes relativas a estágio na disciplina Nutrição da Gestante e Puerpério.

Deve ser lembrado que a solicitação de prática ou estágio em determinada disciplina, onde já existe esta modalidade de ensino, talvez se deva ao estímulo despertado no aluno por ele.

Os resultados obtidos mostram que 0 ensino de Nutrição nas escolas de Enfermagem não é uniforme em termos de disciplinas e forma de ensino, o que naturalmente condiciona a percepção das necessidades expressas pelos alunos.

A disciplina que aparentemente requer atenção prioritária é Nutriçāo em Saúde Pública, que, além de praticamente não ser ministrada, apresenta elevado índice de sugestōes, especialmente quanto ao estágio. 
MATTOS, L.U. e colaboradores - Ensino de nutriçāo nas escolas de enfermagem do Estado de Sāo Paulo. Rev. Bras. Enf.; DF, 29 : 115-126, 1976.

Quanto à forma, verifica-se pelos dados obtidos, que no ensino das disciplinas da Nutrição, inexiste homogeneidade por escola e/ou disciplina, sendo uma mesma disciplina ministrada de forma diversa nas escolas pesquisadas.

A observação das sugestōes apresentadas pelos estudantes, evidencia que há uma tendência generalizada de as ne- cessidades sentidas voltarem-se para a modalidades de ensino prático e estágio.

Acredita-se que a utilização das informações obtidas na elaboração dos programas de ensino de Nutrição poderia colaborar no aprimoramento da formação do enfermeiro, no que se refere ao seu preparo para poceder ao cuidacc nutricional do paciente.

\section{REFERENCLAS BIBLIOGRAFICAS}

CICONELI, M. I., et al papéis e funçōes das enfermeiras do Hospital das Clinicas de Ribeirāo Preto. In: SEMINARIO SOBRE FDUCAÇAO EM ENFERMAGEM, 2. ${ }^{\circ}$ 11-18 nov. 1970. Ribeirāo Preto - Relatório. Ribeirāo Preto, Escola de Enfermagem de Ribeirāo Preto da USP, OPAS/OMS, 1970. p. 33-46.

COELFO, G. G. D. et al O papel da enfermeira na assistência materno-infantil. In: SFMINARIO SOBRE EDUCAÇAO
EM ENFERMAGEM, 2., $11-18$ nov. 1970, Ribeirāo Preto - Relatório. Ribeirāo Preto, Escola de Enfermagem de Ribeirāo Preto da USP, OPAS-OMS, 1970. p. 77-86.

HARRISON, C. G., et al Public health nurses' knowledge of nutrition. Journ. of Am. Diet. Assoc. 55:133-139, 1969.

SPECIAL communication Extenling the scope of nursing practice - A report of the secretary's Comittee to study extended roles for nurses. JAMA. 220(9) : 1231-1235, 1972. 
MATTOS, L.U. e colaboradores - Ensino de nutrição nas escolas de enfermagem do Estado de São Paulo. Rev. Bras. Ene.; DF, 29 : 115-126, 1976.

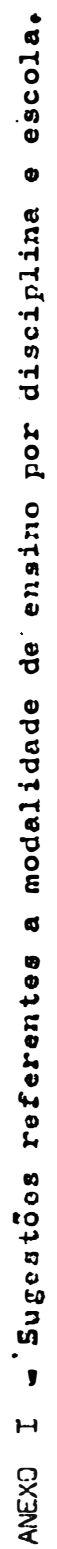

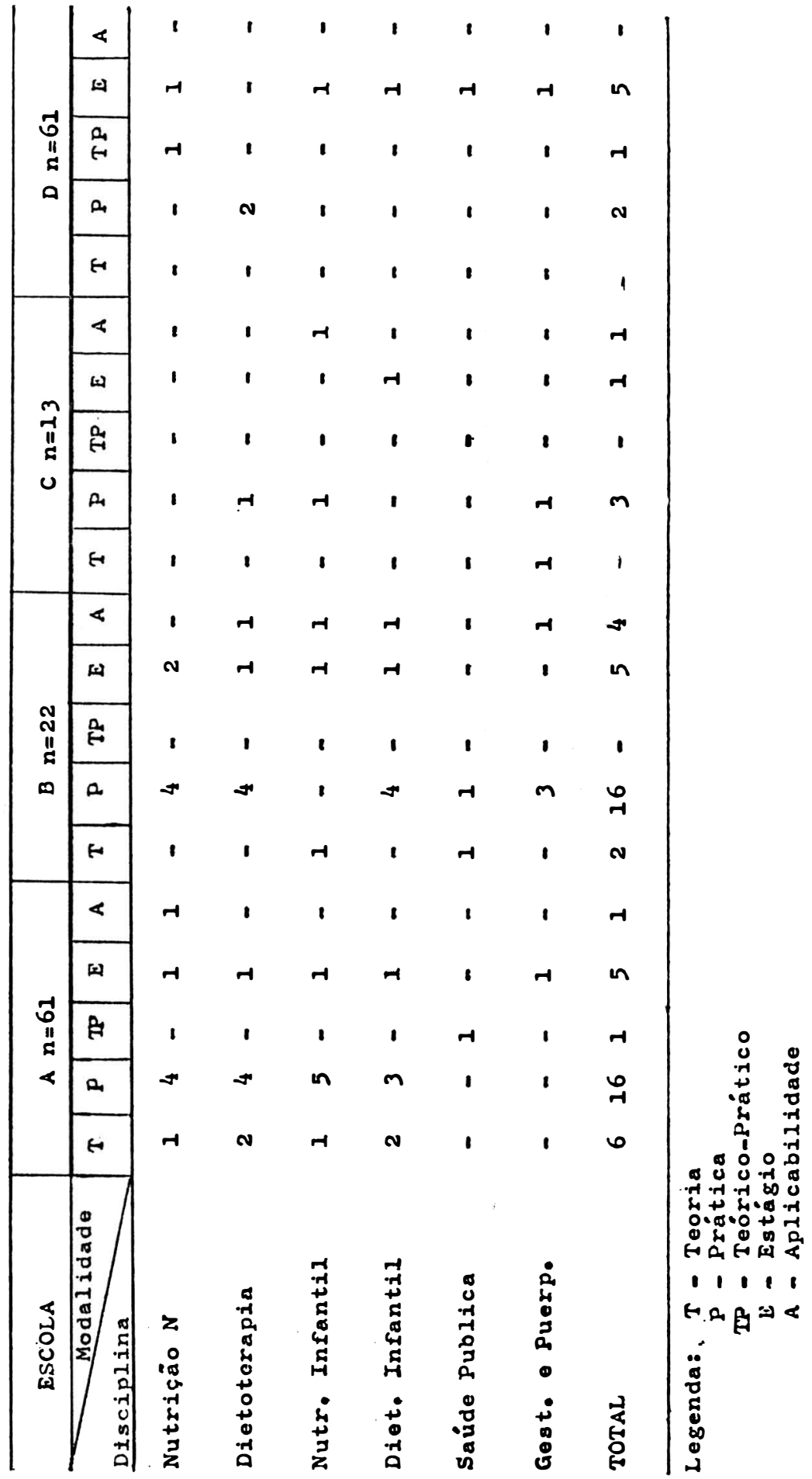


MATTOS, L.U. e colaboradores - Ensino de nutrição nas escolas de enfermagem do Estado de Sáo Paulo. Rev. Bras. Ene.; DF, 29 : 115-126, 1976.

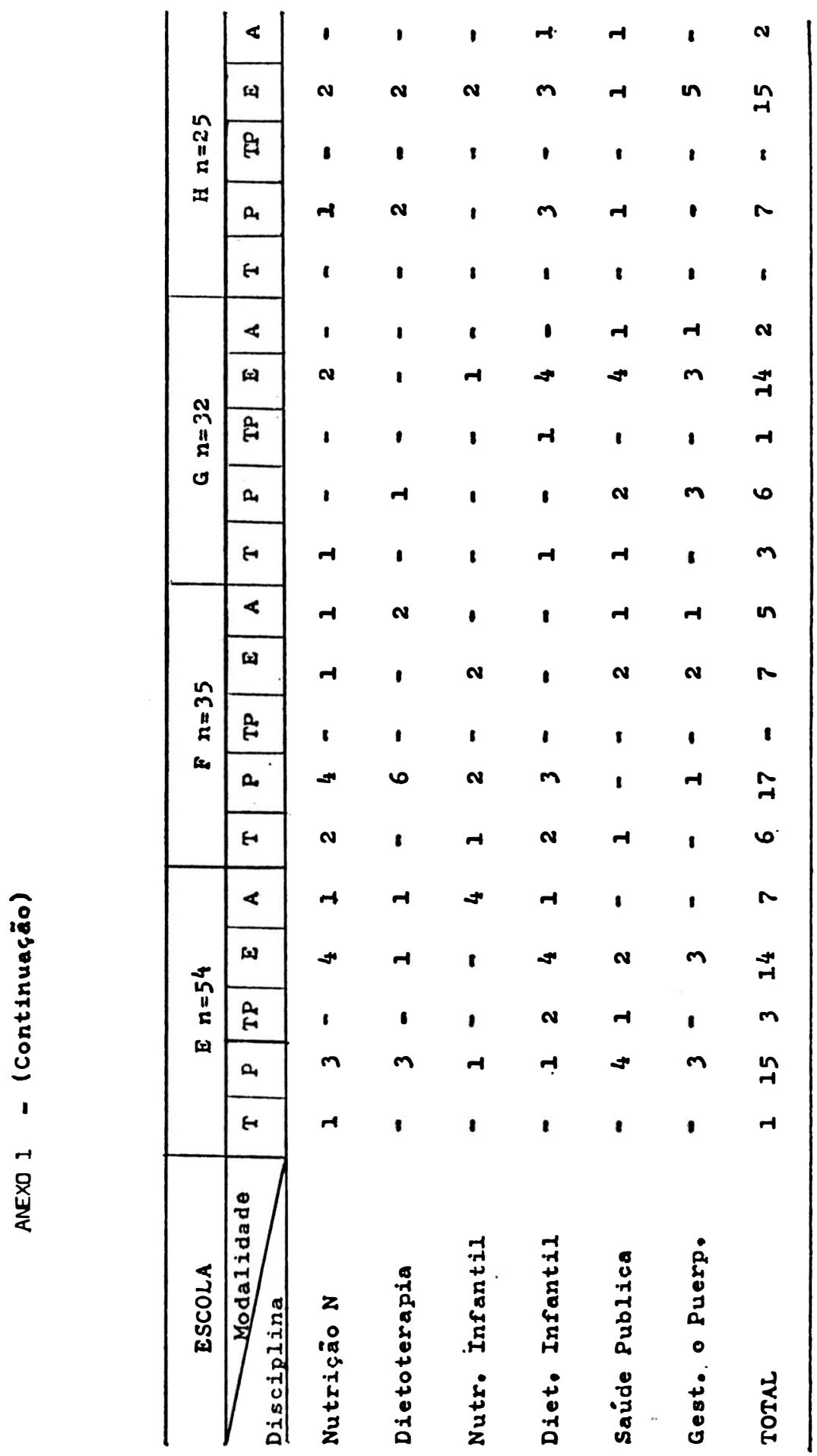

